\title{
Activation of sodium persulfate by magnetic carbon xerogels (CX) CoFe) for the oxidation of bisphenol A: Process variables effects, matrix effects and reaction pathways
}

\author{
Alexandra Outsiou ${ }^{a}$, Zacharias Frontistis a, Rui S. Ribeiro b, c, Maria Antonopoulou d, \\ Ioannis K. Konstantinou ${ }^{\mathrm{e}}$, Adrián M.T. Silva ${ }^{\mathrm{c}}$, Joaquim L. Faria ${ }^{\mathrm{c}}$, Helder T. Gomes ${ }^{\text {b', }}$ \\ Dionissios Mantzavinos ${ }^{\text {a, * }}$ \\ a Department of Chemical Engineering, University of Patras, Caratheodory 1, University Campus, GR-26504 Patras, Greece \\ ${ }^{\mathrm{b}}$ Laboratory of Separation and Reaction Engineering - Laboratory of Catalysis and Materials (LSRE-LCM), Escola Superior de Tecnologia e Gestão, Instituto \\ Politécnico de Bragança, Campus de Santa Apolónia, 5300-253 Bragança, Portugal \\ ${ }^{c}$ Laboratory of Separation and Reaction Engineering - Laboratory of Catalysis and Materials (LSRE-LCM), Faculdade de Engenharia, Universidade do Porto, \\ Rua Dr. Roberto Frias, 4200-465 Porto, Portugal \\ d Department of Environmental and Natural Resources Management, University of Patras, 2 Seferi St., GR-30100 Agrinio, Greece \\ e Department of Chemistry, Laboratory of Industrial Chemistry, University of Ioannina, GR-45110 Ioannina, Greece
}

\section{A R T I C L E I N F O}

\section{Article history:}

Received 23 May 2017

Received in revised form

17 July 2017

Accepted 18 July 2017

Available online 24 July 2017

\section{Keywords:}

Chloride

Endocrine disruptors

Fenton-like

Intermediates

Operating parameters

Radicals

\begin{abstract}
A B S T R A C T
An advanced oxidation process comprising sodium persulfate (SPS) and a novel magnetic carbon xerogel was tested for the degradation of bisphenol A (BPA), a model endocrine-disrupting compound. The catalyst, consisting of interconnected carbon microspheres with embedded iron and cobalt microparticles, was capable of activating persulfate to form sulfate and hydroxyl radicals at ambient conditions.

The pseudo-first order degradation rate of BPA in ultrapure water (UPW) was found to increase with (i) increasing catalyst $(25-75 \mathrm{mg} / \mathrm{L})$ and SPS $(31-250 \mathrm{mg} / \mathrm{L})$ concentrations, (ii) decreasing BPA concentration (285-14,200 $\mu \mathrm{g} / \mathrm{L}$ ), and (iii) changing $\mathrm{pH}$ from alkaline to acidic values (9-3).

Besides UPW, tests were conducted in drinking water, treated wastewater, groundwater and surface water; interestingly, the rate in UPW was always lower than in any other matrix containing several organic and inorganic constituents. The effect of natural organic matter (in the form of humic acids) and alcohols was detrimental to BPA degradation owing to the scavenging of radicals. Conversely, chlorides at concentrations greater than $50 \mathrm{mg} / \mathrm{L}$ had a positive effect due to the formation and subsequent participation of chlorine-containing radicals.

Liquid chromatography time-of-flight mass spectrometry was employed to identify major transformation by-products (TBPs) of BPA degradation in the absence and presence of chlorides; in the latter case, several chlorinated TBPs were detected confirming the role of Cl-related radicals. Based on TBPs, main reaction pathways are proposed.
\end{abstract}

(C) 2017 Elsevier Ltd. All rights reserved.

\section{Introduction}

In recent years, the use of persulfate as a source of reactive sulfate radicals (equation (1)) has been considered an efficient advanced oxidation process (AOP) for water and wastewater treatment (Matzek and Carter, 2016):

\footnotetext{
* Corresponding author.

E-mail address: mantzavinos@chemeng.upatras.gr (D. Mantzavinos).
}

$\mathrm{S}_{2} \mathrm{O}_{8}{ }^{2-}+$ Activator $\rightarrow\left[\mathrm{SO}_{4}^{-\bullet}\right.$ or $\left.\mathrm{SO}_{4}{ }^{2-}\right]$

Persulfate exhibits several advantages due to its moderate cost, high stability and aqueous solubility, as well as to the fact that it is solid at ambient temperature, which facilitates its transport and storage (Lin et al., 2011). Nonetheless, persulfate itself is a moderate oxidizing agent $\left(\mathrm{E}^{\mathrm{O}}=2.01 \mathrm{~V}\right)$ and it must be activated to generate sulfate radicals $\left(E^{0}=2.5-3.1 \mathrm{~V}\right)$, which typically react $103-105$ times faster than the anion persulfate (Tsitonaki et al., 2010). Persulfate activation can be achieved by several means including heat, 
UV light, ultrasound, microwaves and through one-electron transfer using metals such as iron, cobalt, copper, zinc and manganese (Matzek and Carter, 2016). Persulfate activation by transition metals and, ferrous ion in particular, has extensively been investigated mimicking classical Fenton reactions (Liu et al., 2014) (equations (2)-(4)):

$\mathrm{S}_{2} \mathrm{O}_{8}{ }^{2-}+\mathrm{Fe}^{2+} \rightarrow \mathrm{SO}_{4}{ }^{--}+\mathrm{SO}_{4}^{2-}+\mathrm{Fe}^{3+}$

$\mathrm{Fe}^{3+}+\mathrm{S}_{2} \mathrm{O}_{8}^{2-} \rightarrow \mathrm{Fe}^{2+}+\mathrm{S}_{2} \mathrm{O}_{8}^{\bullet-}$

Thus, the overall metal-catalyzed decomposition of persulfate can be described as follows:

$2 \mathrm{~S}_{2} \mathrm{O}_{8}{ }^{2-} \stackrel{F e(I I) \leftrightarrow F e(I I I)}{\longrightarrow} \mathrm{SO}_{4}{ }^{\bullet-}+\mathrm{SO}_{4}{ }^{2-}+\mathrm{S}_{2} \mathrm{O}_{8}{ }^{\bullet-}$

In Fenton and alike systems, the use of homogeneous iron (or other ions) typically requires an additional step for the recovery and/or elimination of metals from the treated stream prior to final discharge. Several attempts have been made to overcome this drawback through immobilization of the active phase on a suitable support, i.e. activated carbon, alumina, silica, mesoporous molecular sieves, zeolites, pillared clays and ion-exchange resins (Nidheesh, 2015). Nevertheless, this approach may result in reduced efficiency associated with decreased catalyst stability and/ or increased mass transfer limitations (Ribeiro et al., 2016a).

A set of novel magnetic carbon xerogels, consisting of interconnected carbon microspheres with iron and/or cobalt microparticles embedded in their structure, has recently been prepared by inclusion of iron and/or cobalt precursors during the synthesis of carbon xerogels by polycondensation of resorcinol with formaldehyde, followed by thermal annealing at $800{ }^{\circ} \mathrm{C}$. The catalysts have extensively been characterized and tested successfully for the oxidation of the antibiotic sulfamethoxazole in water using hydrogen peroxide as the source of hydroxyl radicals; these materials exhibited high activity and good stability and they were also magnetically recoverable post-treatment (Ribeiro et al., 2016b).

The work reported in this paper deals for the first time with the use of magnetic carbon xerogels as possible activators of persulfate to oxidize bisphenol A (BPA) in various aqueous matrices. BPA is an emerging micro-contaminant belonging to the family of endocrine disruptors and it has been chosen as a model compound due its excessive usage in plastics manufacturing, as well as additive in brake fluids, thermal papers and flame retardants (Oehlmann et al., 2008). BPA exhibits weak estrogenic activity at concentrations as low as few $n g / L-\mu g / L$, while it is resistant to biodegradation (Vandenberg et al., 2007). It can be released in the environment through various paths including municipal wastewater treatment plant discharges, landfill leachates and spillovers during storage/ transportation (Huang et al., 2012).

The goal of this work was to study the effect of various operating parameters such as the concentration of catalyst, the concentration of persulfate, the concentration of BPA and the solution $\mathrm{pH}$ on the kinetics of degradation. Particular emphasis was given on the effect of the matrix complexity testing several environmentally relevant water matrices. In addition, major transformation by-products were identified and possible reaction pathways and mechanisms were proposed, taking into consideration the interferences of the water matrix constituents.

\section{Materials and methods}

\subsection{Magnetic carbon xerogels}

Experiments were performed with a bimetallic carbon xerogel consisting of interconnected carbon microspheres with iron and cobalt microparticles embedded in their structure ( $\mathrm{CX} / \mathrm{CoFe})$. $\mathrm{Co}$ balt ferrite $\left(\mathrm{CoFe}_{2} \mathrm{O}_{4}\right)$ is the dominant phase. The procedures for catalyst synthesis and characterization are described in detail elsewhere (Ribeiro et al., 2016b).

\subsection{Chemicals}

Bisphenol A (BPA, $\mathrm{C}_{15} \mathrm{H}_{16} \mathrm{O}_{2}$, CAS number: 80-05-7) and sodium persulfate (SPS, $\mathrm{Na}_{2} \mathrm{~S}_{2} \mathrm{O}_{8}, 99+\%$, CAS number: 7775-27-1) were purchased from Merck.

Humic acid (technical grade), hydrogen peroxide (30\%), sodium chloride (99.8\%), sodium hydroxide (98\%), boric acid (>99.8\%) and sulphuric acid (95\%) were also obtained from Merck. Methanol (99.9\%) and t-butanol (99\%) were purchased from Fluka, while potassium dihydrogen phosphate from Millipore.

All chemicals were used as received, without further purification.

\subsection{Water matrices}

BPA solutions were prepared in (i) ultrapure water (UPW); (ii) secondary treated wastewater (WW) collected from the wastewater treatment plant of the University of Patras campus, Greece; (iii) drinking water (DW) obtained from a bottle of the commercially available brand Avra ${ }^{\circledR}$, Greece; (iv) surface water taken from a rivulet in the region of Athens, Greece; (v) groundwater taken from a borehole in the region of Athens, Greece. Properties of the various matrices are summarized in Table 1.

\subsection{Experimental procedure}

In a typical experiment, $120 \mathrm{~mL}$ of an aqueous solution containing the desired concentration of BPA was loaded in a glass cylindrical reaction vessel. The appropriate amount of SPS and the catalyst were then added and the reaction took place under magnetic stirring in open air equilibrium. Unless otherwise stated, the solution was buffered at acidic, near-neutral or alkaline conditions using the appropriate buffers (see section 3.1). Samples of $1.2 \mathrm{~mL}$ were periodically withdrawn from the reactor, quenched with methanol, filtered to remove any solid particles and analyzed by chromatography.

Most of the experiments were performed in duplicate and mean values ( $<5 \%$ difference) are quoted as results.

\subsection{Analytical methods}

High performance liquid chromatography was employed to monitor the concentration of BPA. The analytical protocol (columns, mobile phase, detector) is described in detail elsewhere (Darsinou et al., 2015). The limit of detection was $4.7 \mu \mathrm{g} / \mathrm{L}$ and the limit of quantitation was $12.4 \mu \mathrm{g} / \mathrm{L}$.

Liquid chromatography time-of-flight mass spectrometry (LCTOF-MS) operated in negative ionization mode was used for the identification of transformation by-products (TBPs) as described in detail in our previous work (Darsinou et al., 2015). LC analyses were run with water (LC-MS grade) with $0.01 \%$ formic acid (solvent $A$ ) and acetonitrile (solvent $B$ ) as mobile phase with a flow rate of $0.3 \mathrm{~mL} /$ min. A linear gradient was run as follows: $1 \% \mathrm{~B}$ (initial conditions) to $99 \% \mathrm{~B}$ in $15 \mathrm{~min}$ and then returned to $1 \% \mathrm{~B}$ after $3 \mathrm{~min}$. 
Table 1

Properties of the water matrices used in this work. ND: not determined.

\begin{tabular}{|c|c|c|c|c|c|}
\hline Property & UPW & Wastewater & Drinking water & Surface water & Groundwater \\
\hline $\mathrm{pH}$ & 6 & 8 & 7.5 & 7.5 & 7.4 \\
\hline Conductivity, $\mu \mathrm{S} / \mathrm{cm}$ & 0.056 & 311 & 396 & 491 & 798 \\
\hline $\mathrm{TOC}, \mathrm{mg} / \mathrm{L}$ & & 7 & & 2.7 & 1.9 \\
\hline Bicarbonate, mg/L & & 182 & 211 & ND & ND \\
\hline Chloride, $\mathrm{mg} / \mathrm{L}$ & & 0.5 & 9.8 & 5 & 76 \\
\hline Sulfate, $\mathrm{mg} / \mathrm{L}$ & & 30 & 15 & 274 & 69.5 \\
\hline Nitrate, $\mathrm{mg} / \mathrm{L}$ & & 57 & 5 & & 18.8 \\
\hline
\end{tabular}

\section{Results and discussion}

\subsection{Effect of solution $p H$}

The effect of solution $\mathrm{pH}$ on BPA degradation was studied at three values, i.e. 3, 6 and 9. The results are shown in Fig. 1. Nearneutral and alkaline conditions were achieved using $\mathrm{KH}_{2} \mathrm{PO}_{4}$ and a mixture of $\mathrm{NaOH}$ and $\mathrm{H}_{3} \mathrm{BO}_{3}$ as buffers, respectively, while acidic conditions were achieved adding $\mathrm{H}_{2} \mathrm{SO}_{4}$, which also served as buffer; in all cases, the $\mathrm{pH}$ remained unchanged during the reaction. Although complete BPA degradation can be achieved within 45-60 min regardless of the starting solution $\mathrm{pH}$, the initial rate decreases with increasing $\mathrm{pH}$.

The point of zero charge of the catalyst is 7.7 (Ribeiro et al., 2016b), therefore, it is positively charged at $\mathrm{pH}<7.7$. Consequently, the adsorption and subsequent activation of persulfate anions onto the catalysts is favored at $\mathrm{pH}$ values of 3 and 6 due to the electrostatic attraction between the catalyst surface and the persulfate ions but it decreases at $\mathrm{pH}=9$ due to electrostatic repulsion. In addition, the presence of insoluble forms of $\mathrm{Fe}(\mathrm{II}) /$ $\mathrm{Fe}(\mathrm{III})$ under neutral and alkaline $\mathrm{pH}$ could be also considered for the slower kinetics obtained at $\mathrm{pH} 6$ and 9.

Furthermore, BPA whose pKa is 9.6-10.2 (Bautista-Toledo et al., 2005), is negatively charged at alkaline $\mathrm{pH}$ range above the $\mathrm{pKa}$ value, therefore, an electrostatic repulsion between the substrate and the catalyst cannot be considered to affect significantly the degradation kinetics and thus the decreased reactivity recorded at $\mathrm{pH}=9$.

Finally, sulfate radicals react with water at all $\mathrm{pH}$ values leading to the formation of hydroxyl radicals, which become the main oxidizing species at alkaline conditions (Matzek and Carter, 2016; Zhao et al., 2014), according to equations (5) and (6):

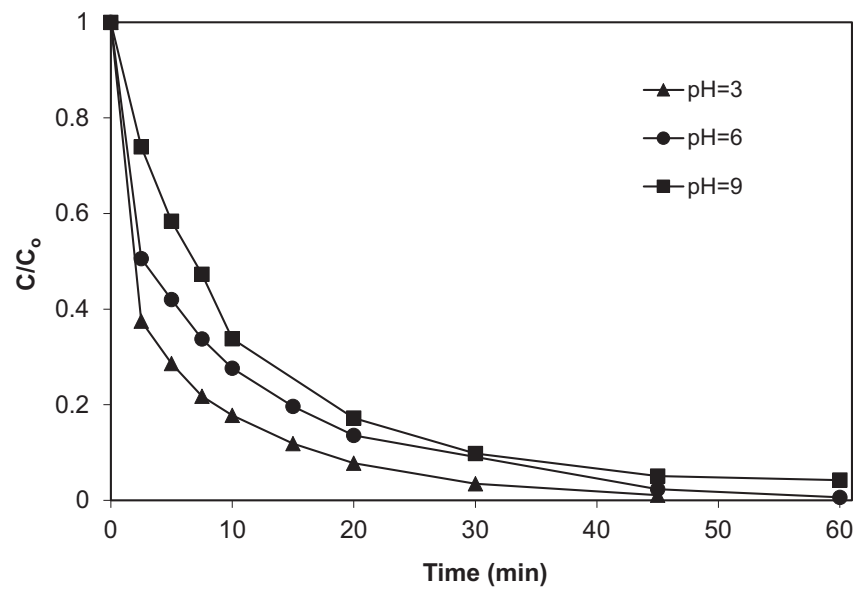

Fig. 1. Effect of buffered solution $\mathrm{pH}$ on $285 \mu \mathrm{g} / \mathrm{L}$ BPA degradation with $75 \mathrm{mg} / \mathrm{L} \mathrm{CX} /$ CoFe and $250 \mathrm{mg} / \mathrm{L}$ SPS in UPW.
$\mathrm{SO}_{4}{ }^{\bullet-}+\mathrm{H}_{2} \mathrm{O} \rightarrow \mathrm{SO}_{4}{ }^{2-}+\cdot \cdot \mathrm{OH}+\mathrm{H}^{+}$

$\mathrm{SO}_{4}{ }^{\bullet-}+\mathrm{OH}^{-} \rightarrow \mathrm{SO}_{4}{ }^{2-}+\cdot{ }^{\bullet} \mathrm{OH}$

Although sulfate radicals have a lower redox potential than hydroxyl radicals, they are more selective towards certain organics (Darsinou et al., 2015; Lutze et al., 2015) and this may justify the reactivity recorded at lower $\mathrm{pH}$ values, where sulfate radicals prevail.

Additional experiments (not shown for brevity) were performed adjusting but not buffering the initial solution $\mathrm{pH}$ from its inherent value of $6-9$ (with $\mathrm{NaOH}$ ) or 3 (with $\mathrm{H}_{2} \mathrm{SO}_{4}$ ). For the run at $\mathrm{pH}_{0}=6$, the value rapidly dropped to 4.3 within the first 2 min of reaction and eventually stabilized to $4 \pm 0.2$ for the rest of the reaction; at these conditions, the BPA degradation profile nearly matched that at $\mathrm{pH}_{\mathrm{o}}=3$. For the run at $\mathrm{pH}_{\mathrm{o}}=9$, the degradation was always 15-20\% lower than at the other two pHs, with pH dropping and stabilizing at near-neutral values.

These results indicate that the proposed treatment system can function efficiently in a wide range of $\mathrm{pH}$ values, which makes its application feasible for water/wastewater treatment without the need for $\mathrm{pH}$ buffering or adjustment (i.e. at the sample's natural $\mathrm{pH}$ ). However and for the purposes of this study, all subsequent experiments were performed at $\mathrm{pH}=3$ in order to eliminate the effect of $\mathrm{pH}$ change during the reaction.

\subsection{Effect of catalyst and SPS concentration}

Based on the knowledge for Fenton and Fenton-like reactions in which the concentration levels of the catalyst and the oxidant are crucial to process performance, the effect of these parameters are also studied herein. Fig. 2 shows the beneficial effect of increasing catalyst concentration in the range $25-75 \mathrm{mg} / \mathrm{L}$ on the degradation of $285 \mu \mathrm{g} / \mathrm{L}$ BPA. Considering that BPA concentration-time profiles can be fitted adequately (i.e. the linear regression coefficient, $\mathrm{r}^{2}$, is $>95 \%$ ) to a pseudo-first order rate expression (equation (7)):

$\ln \frac{C_{o}}{C}=k_{a p p} t \Leftrightarrow \ln (1-X)=-k_{\text {app }} t$

the apparent rate constant for BPA degradation, $k_{a p p}$, is computed equal to $0.013,0.038$ and $0.094 \mathrm{~min}^{-1}$ at 25,50 and $75 \mathrm{mg} / \mathrm{L}$ catalyst concentration, respectively. In the absence of catalyst, SPS cannot be activated to form radicals and this is consistent with the low extent (ca 10\%) of BPA degradation recorded (this is due to the fact that SPS itself is a mild oxidant).

Figure 3 shows the effect of changing SPS concentration in the range $31-500 \mathrm{mg} / \mathrm{L}$ on the degradation of $285 \mu \mathrm{g} / \mathrm{L} \mathrm{BPA}$. The computed $k_{\text {app }}$ values according to equation (7) are 0.054, 0.069, $0.086,0.093$ and $0.046 \mathrm{~min}^{-1}$ at 31, 62.5, 125, 250 and $500 \mathrm{mg} / \mathrm{L}$ SPS, respectively (the linear regression coefficient, $r^{2}$, is $>97 \%$ ). Degradation increases with increasing SPS concentration up to a 


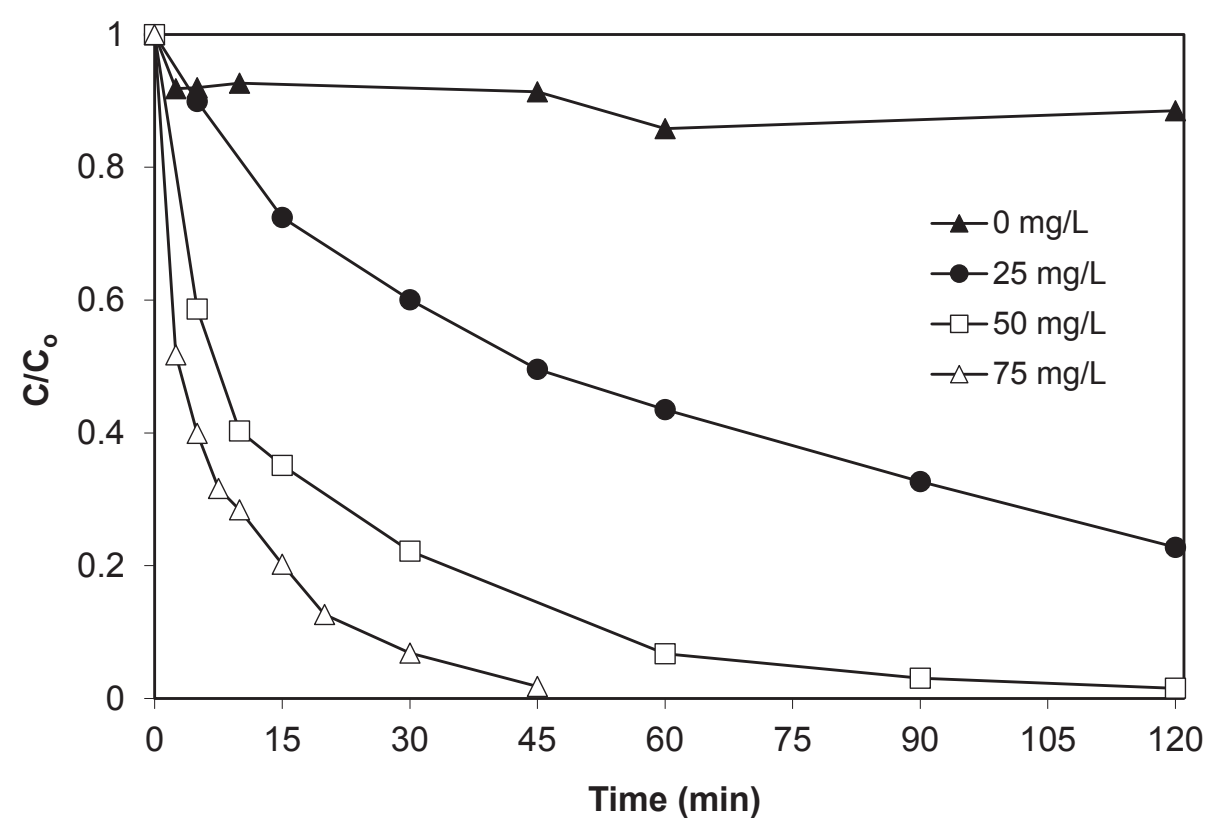

Fig. 2. Effect of $\mathrm{CX} / \mathrm{CoFe}$ concentration on $285 \mu \mathrm{g} / \mathrm{L}$ BPA degradation with $250 \mathrm{mg} / \mathrm{L}$ SPS in UPW and $\mathrm{pH}=3$.

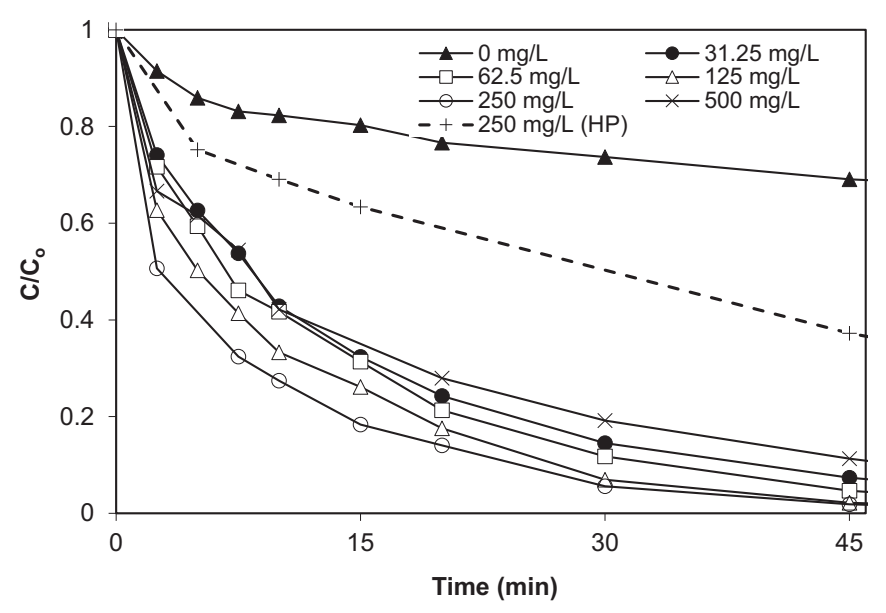

Fig. 3. Effect of SPS concentration on $285 \mu \mathrm{g} / \mathrm{L}$ BPA degradation with $75 \mathrm{mg} / \mathrm{L}$ CX/CoFe in UPW and $\mathrm{pH}=3$. Dashed line shows experiment with $250 \mathrm{mg} / \mathrm{L}$ hydrogen peroxide (HP) in otherwise identical conditions.

point, beyond which the effect becomes detrimental; it is welldocumented (Dewil et al., 2017) that an excess of oxidant in Fenton and alike systems may result in radical self-scavenging effects, thus decreasing performance. From the experiment without SPS, it is evident that BPA is partly adsorbed onto the catalyst surface (i.e. $30 \%$ after $45 \mathrm{~min}$, which is extended to $35 \%$ after $90 \mathrm{~min}$ (not shown in Fig. 3).

We have recently demonstrated (Ribeiro et al., 2016b) that carbon xerogels are effective heterogeneous Fenton catalysts for the degradation of antibiotics in various matrices. In this light, an additional experiment was performed replacing SPS with an equal concentration of $\mathrm{H}_{2} \mathrm{O}_{2}$; as can be seen in Fig. 3, the reaction with $250 \mathrm{mg} / \mathrm{L} \mathrm{H}_{2} \mathrm{O}_{2}$ is substantially slower leading to only 63\% BPA degradation after $45 \mathrm{~min}$.

\subsection{Effect of BPA concentration}

Although the pseudo-first order approach is useful to depict apparent rate constants and, consequently, quantify kinetics, this does not necessarily imply that the reaction is indeed true first order with respect to the substrate. This is clearly demonstrated in Fig. 4 where the time needed to achieve a certain BPA conversion, $\mathrm{X}$ (see also equation (7)), depends on its initial concentration. For example, the time needed to achieve $85 \%$ BPA conversion is 15,45 and $120 \mathrm{~min}$ at 285, 570 and $855 \mu \mathrm{g} / \mathrm{L}$ BPA concentration, respectively; moreover, the corresponding $k_{a p p}$ are also concentrationdependent taking values of $0.093,0.042$ and $0.019 \mathrm{~min}^{-1}\left(\mathrm{r}^{2}\right.$ is $>94 \%)$. As the amount of generated oxidizing species available to react with the substrate mainly depends on the operating conditions (i.e. catalyst and SPS concentration, $\mathrm{pH}$ ), kinetics will predominantly be dictated by the substrate concentration; as the latter increases, the reaction order will shift to lower values and, eventually, become zero.

Although a proper kinetic analysis is outside the scope of this work, the authors would like to emphasize a common misconception made by several researchers in the field concerning the difference between (i) apparent and true rate orders, and (ii) kinetic modeling and data fitting. In several cases, such mistakes are triggered by the unrealistically high contaminant concentrations, e.g. in the order of $\mathrm{mg} / \mathrm{L}$, employed in advanced oxidation studies. Fig. 4 also shows an experiment at $14.2 \mathrm{mg} / \mathrm{L}$ BPA concentration leading to just $30 \%$ degradation after $120 \mathrm{~min}$. The run was repeated doubling the SPS $(500 \mathrm{mg} / \mathrm{L})$ and catalyst $(150 \mathrm{mg} / \mathrm{L})$ concentrations and extended to 420 min after which BPA degradation was just 50\% (run not shown for brevity).

\subsection{The water matrix effect}

The majority of published research on AOPs for water remediation is being performed in model aqueous solutions containing the contaminant under consideration. Most commonly, the contaminant is spiked in ultrapure water (UPW) at concentrations that typically are several orders of magnitude greater than those found in actual environmental samples (see section 3.3). This approach has certain advantages since (i) it eliminates the interactions amongst the contaminant, the oxidative species and the constituents of more complex matrices (i.e. surface water, groundwater, 


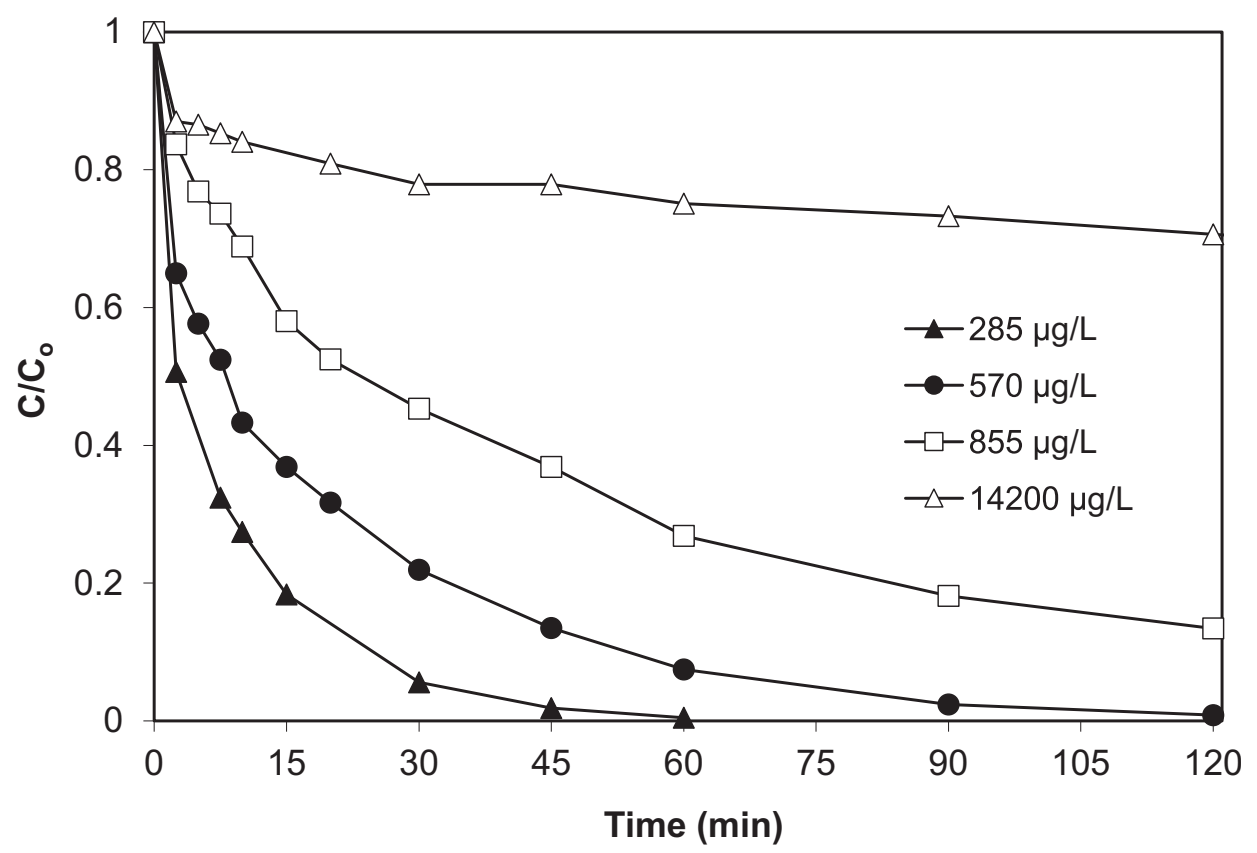

Fig. 4. Effect of initial BPA concentration on its degradation with $75 \mathrm{mg} / \mathrm{L} \mathrm{CX} / \mathrm{CoFe}$ and $250 \mathrm{mg} / \mathrm{L}$ SPS in UPW and $\mathrm{pH}=3$.

municipal wastewater), (ii) it does not require sophisticated and laborious analytical techniques to monitor trace amounts of the contaminant.

The quality of the actual water matrix is critical since not taking into account the various interactions is likely to lead to false conclusions. As a rule of thumb, degradation kinetics decrease with increasing matrix complexity mainly because the matrix may contain several non-target organic and inorganic constituents that compete with the target molecule(s) for the oxidizing species.

Fig. 5 shows BPA degradation in various water matrices such as UPW, drinking water (DW), surface water taken from a rivulet, groundwater and secondary treated wastewater (WW). Although complete BPA degradation can be achieved within 30-45 min of reaction irrespective of the matrix employed, the initial rate clearly depends on it. Interestingly, and unlikely to what was expected, the reaction in UPW is slower than in any other matrix including WW, which contains, besides various inorganic anions, organic carbon in the order of $10 \mathrm{mg} / \mathrm{L}$.

Humic acids and low molecular weight organic acids such as oxalate are able to form complexes with iron and iron oxides, thus promoting the Fenton-like oxidation processes. On the contrary, the presence of organic matter and inorganic anions could result in competitive adsorption in relation to persulfate anions and substrate onto the xerogel surface, as well as in scavenging of the

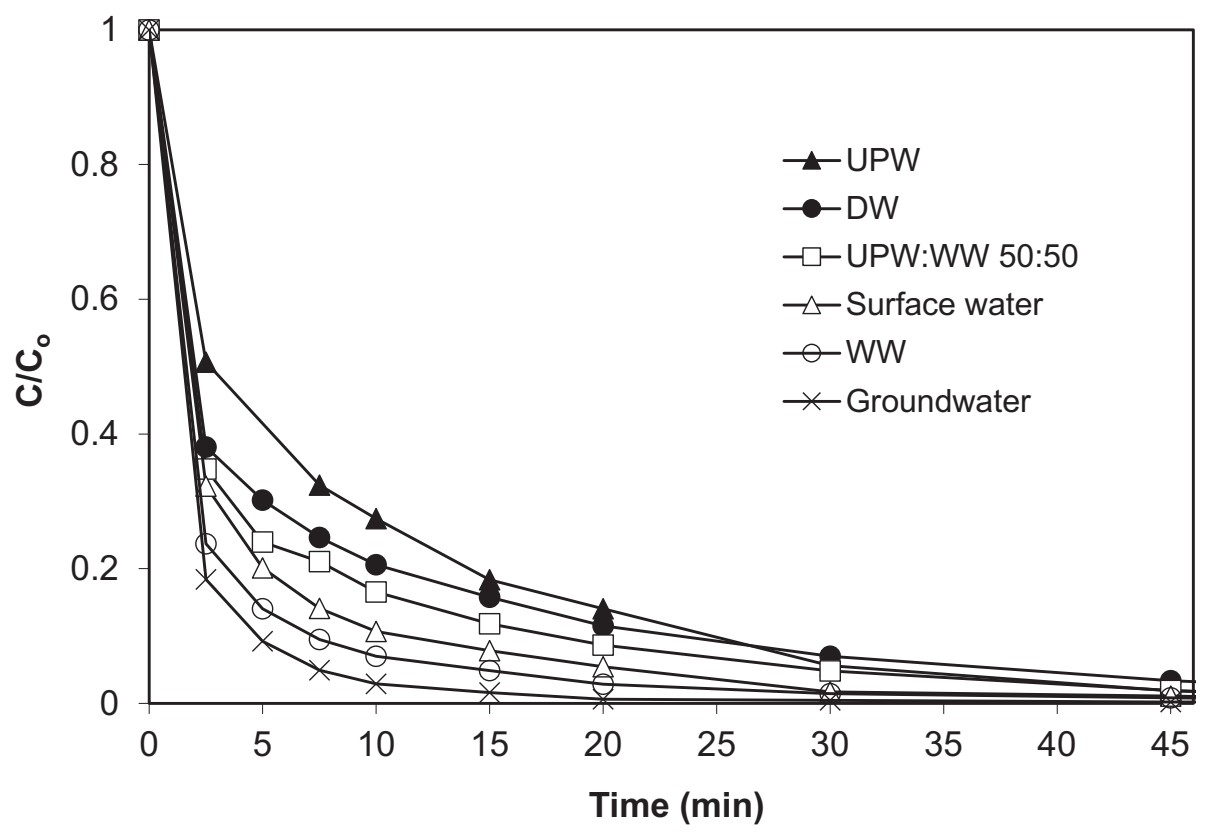

Fig. 5. Effect of actual water matrix on $285 \mu \mathrm{g} / \mathrm{L}$ BPA degradation with $75 \mathrm{mg} / \mathrm{L} \mathrm{CX/CoFe,} 250 \mathrm{mg} / \mathrm{L}$ SPS and pH $=3$. 


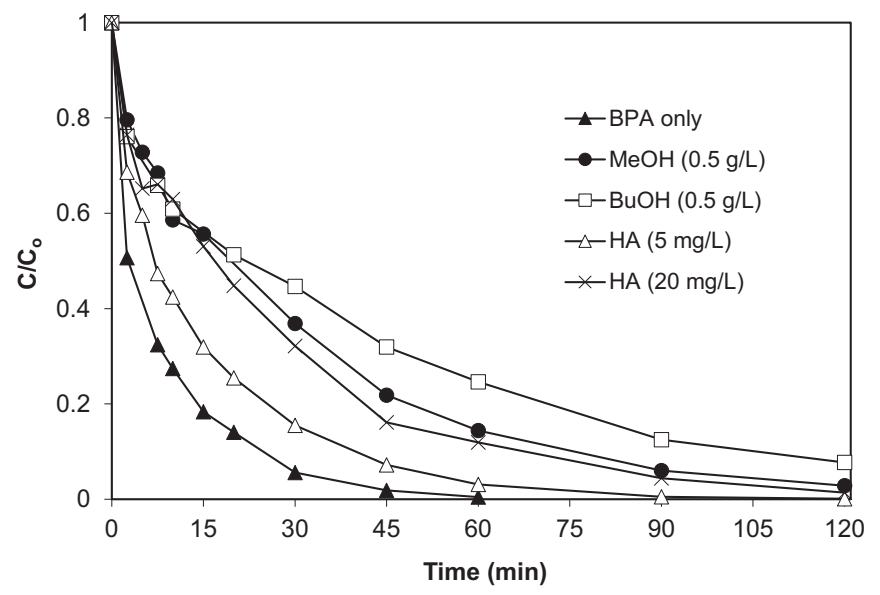

Fig. 6. Effect of organics on $285 \mu \mathrm{g} / \mathrm{L}$ BPA degradation with $75 \mathrm{mg} / \mathrm{L} \mathrm{CX} / \mathrm{CoFe}$ and $250 \mathrm{mg} / \mathrm{L}$ SPS in UPW and $\mathrm{pH}=3$.

produced radicals. The observed kinetics is the overall result of interplay among the previous effects and thus we attempted to discriminate the role of the major constituents.

\subsubsection{The role of organic constituents}

To check the effect of the organic matter, experiments were conducted adding humic acid (HA) in UPW, a representative of the organic matter typically found in natural waters and wastewaters and the results are shown in Fig. 6. The apparent rate constant of BPA degradation in UPW is $0.093 \mathrm{~min}^{-1}$ and it decreases to 0.058 and $0.036 \mathrm{~min}^{-1}$ in the presence of 5 and $20 \mathrm{mg} / \mathrm{L} \mathrm{HA}$, respectively. It should be noted here that the organic carbon content of $20 \mathrm{mg} / \mathrm{L}$ HA is nearly equal to that found in WW. Additional experiments were performed with methanol and t-butanol, which are typical radical scavengers showing different affinity to hydroxyl and sulfate radicals; methanol reacts with the former 300 times faster than with the latter, while t-butanol 1900 times faster (Qi et al., 2015). The presence of both alcohols retards BPA degradation (the rate constants are 0.031 and $0.023 \mathrm{~min}^{-1}$ with methanol and t-butanol,
Table 2

High resolution accurate mass data $\left([\mathrm{M}-\mathrm{H}]^{-}\right.$, and relative error $\left.\Delta(\mathrm{ppm})\right)$ for BPA and TBPs (a) in the absence of $\mathrm{NaCl}$, and (b) in the presence of $\mathrm{NaCl}$.

\begin{tabular}{lllll}
\hline TBP code & Ion elemental composition & $\mathrm{m} / \mathrm{z}[\mathrm{M}-\mathrm{H}]^{-}$ & $\Delta(\mathrm{ppm})$ & Process \\
\hline BPA & $\mathrm{C}_{15} \mathrm{H}_{15} \mathrm{O}_{2}$ & 227.1074 & 1.6 & \\
TBP1 & $\mathrm{C}_{15} \mathrm{H}_{13} \mathrm{O}_{4}$ & 257.0821 & -0.6 & $\mathrm{a}$ \\
TBP2 & $\mathrm{C}_{18} \mathrm{H}_{21} \mathrm{O}_{4}$ & 301.1443 & 0.9 & $\mathrm{a}$ \\
TBP3 & $\mathrm{C}_{15} \mathrm{H}_{13} \mathrm{O}_{3}$ & 241.0876 & -2.4 & a,b \\
TBP4 & $\mathrm{C}_{15} \mathrm{H}_{15} \mathrm{O}_{3}$ & 243.1028 & -0.3 & a,b \\
TBP5 & $\mathrm{C}_{24} \mathrm{H}_{25} \mathrm{O}_{4}$ & 377.1744 & 3.7 & a,b \\
TBP6 & $\mathrm{C}_{15} \mathrm{H}_{14} \mathrm{ClO}_{2}$ & 261.0675 & 4.8 & b \\
TBP7 & $\mathrm{C}_{15} \mathrm{H}_{13} \mathrm{Cl}_{2} \mathrm{O}_{2}$ & 295.0297 & 0.4 & b \\
TBP8 & $\mathrm{C}_{30} \mathrm{H}_{29} \mathrm{O}_{4}$ & 453.2059 & 2.8 & a,b \\
TBP9 & $\mathrm{C}_{60} \mathrm{H}_{57} \mathrm{O}_{8}$ & 905.4019 & 4.4 & a,b \\
TBP10 & $\mathrm{C}_{30} \mathrm{H}_{28} \mathrm{ClO}_{4}$ & 487.1682 & -0.1 & b \\
TBP11 & $\mathrm{C}_{30} \mathrm{H}_{29} \mathrm{O}_{4}$ & 453.2057 & 3.9 & a,b \\
TBP12 & $\mathrm{C}_{30} \mathrm{H}_{27} \mathrm{Cl}_{2} \mathrm{O}_{4}$ & 521.1280 & 2.4 & b \\
TBP13 & $\mathrm{C}_{45} \mathrm{H}_{43} \mathrm{O}_{6}$ & 679.3059 & 0.8 & a,b \\
TBP14 & $\mathrm{C}_{45} \mathrm{H}_{42} \mathrm{ClO}_{6}$ & 713.2649 & 3.7 & b \\
TBP15 & $\mathrm{C}_{45} \mathrm{H}_{43} \mathrm{O}_{6}$ & 679.3041 & 3.6 & a,b \\
TBP16 & $\mathrm{C}_{45} \mathrm{H}_{43} \mathrm{O}_{6}$ & 679.3065 & 0 & a,b \\
TBP17 & $\mathrm{C}_{45} \mathrm{H}_{42} \mathrm{ClO}_{6}$ & 713.2675 & 0.1 & b \\
\hline
\end{tabular}

respectively), indicating that both sulfate and hydroxyl radicals are responsible for BPA degradation. From the results of Figs. 5 and 6, it is inferred that the beneficial water matrix effect on BPA degradation cannot be ascribed to the presence of non-target organic constituents as these appear to compete directly with BPA for the oxidizing species. This is also consistent with the effect of initial BPA concentration on its degradation, particularly at excessive concentrations as depicted in Fig. 4.

\subsubsection{The role of chloride ion}

Various ions naturally occurring in water matrices may affect the performance of activated persulfate oxidation with bicarbonate and chloride ions playing an important role. The way these ions interfere with the process is case-specific depending on the persulfate activation method, the type of substrate, the complexity of the water matrix and the concentration levels of the ions under consideration; in this respect, it is not surprising that various studies have reported both detrimental and beneficial effects of

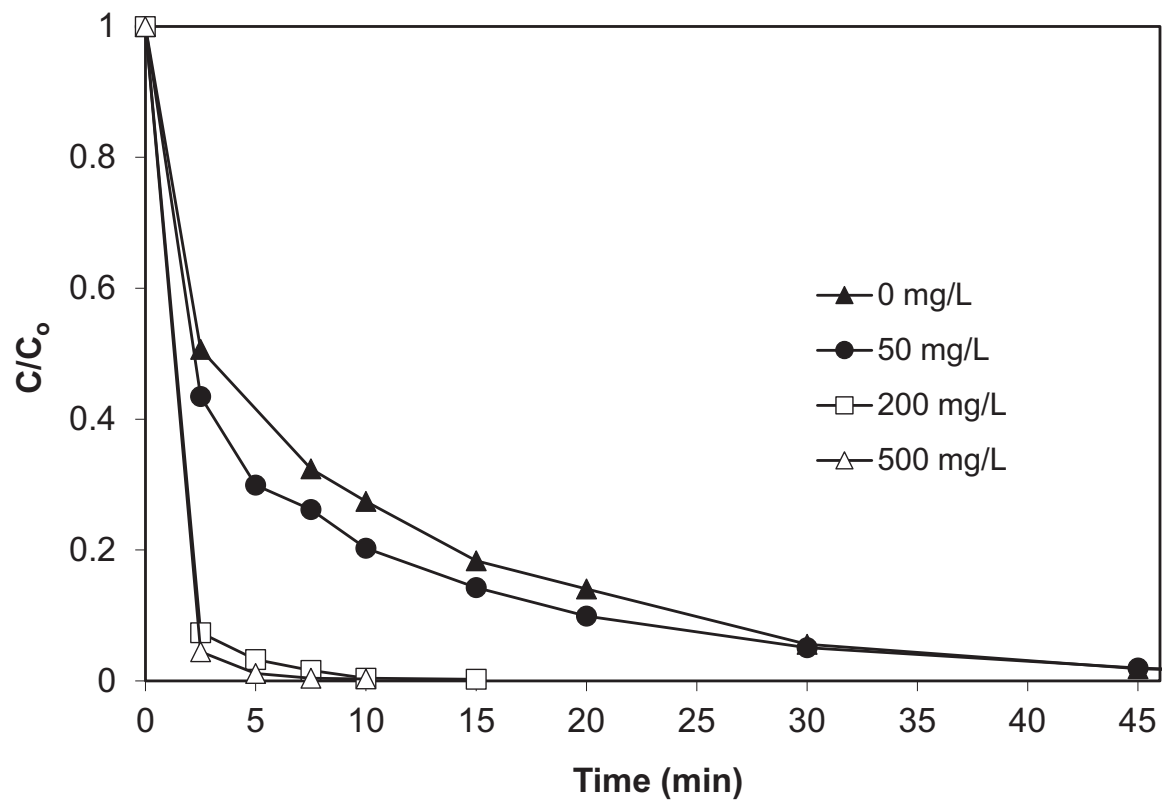

Fig. 7. Effect of $\mathrm{NaCl}$ on $285 \mu \mathrm{g} / \mathrm{L} \mathrm{BPA}$ degradation with $75 \mathrm{mg} / \mathrm{L} \mathrm{CX} / \mathrm{CoFe}$ and $250 \mathrm{mg} / \mathrm{L}$ SPS in UPW and $\mathrm{pH}=3$. 
<smiles>CC(C)(c1ccc(O)cc1)c1ccc(O)cc1</smiles>

BPA

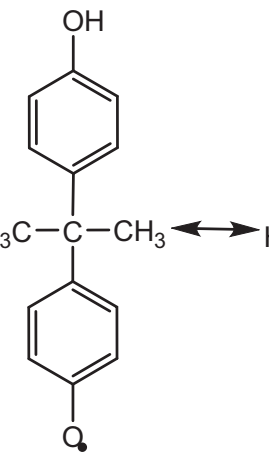

(I)<smiles>CC(C)(C1=CCC(=O)C=C1)c1ccc(O)cc1</smiles>

(II)<smiles>CC(/C=C/C(=C/O)c1cc(C(C)(C)c2ccc(O)c(-c3cc(C(C)(C)c4ccc(O)cc4)ccc3O)c2)ccc1O)=C\C(C)c1ccc(O)cc1</smiles><smiles>CC(C)(C)c1ccc(O)cc1</smiles>

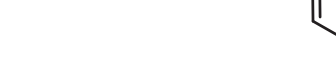

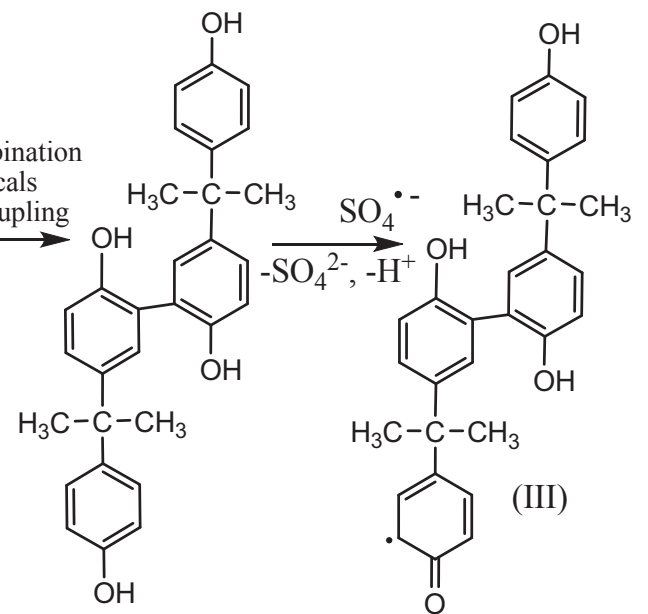

TBP8, TBP11 C-C Coupling (II),(III) radicals

II radicals C-C coupling<smiles>CC(C)(c1ccc(O)cc1)c1ccc(O)c(-c2cc(C(C)(C)c3ccc(O)c(-c4cc(C(C)(C)c5ccc(O)cc5)ccc4O)c3)ccc2O)c1</smiles>

TBP13, TBP15, TBP16

Fig. 8. BPA transformation pathways by BPA-radical coupling during treatment with $\mathrm{CX} / \mathrm{CoFe}$ and SPS in the presence and absence of NaCl.

ions on substrate degradation (Matzek and Carter, 2016; Lutze et al., 2015; Bennedsen et al., 2012; Fang et al., 2012).

The effect of chloride in the range $50-500 \mathrm{mg} / \mathrm{L}$ on BPA degradation over the $\mathrm{CX} / \mathrm{CoFe}$ catalyst is shown in Fig. 7. The reaction rate increases by as much as six times when the solution is added $200 \mathrm{mg} / \mathrm{L}$ chloride, while a higher concentration of $500 \mathrm{mg} / \mathrm{L}$ does not accelerate the reaction further. Blank experiments were also performed (not shown for brevity) with $\mathrm{NaCl}$ alone (i.e. without catalyst and SPS) and $\mathrm{NaCl}$ and SPS (i.e. without catalyst) yielding no BPA degradation.

Sulfate radicals primarily react with chloride to form chlorine radicals (equation (8)) that further react with chloride to form the dichloride radical (equation (9)) (Lutze et al., 2015; Bennedsen et al., 2012; Fang et al., 2012):
$\mathrm{SO}_{4}{ }^{-+}+\mathrm{Cl}^{-} \rightleftarrows \mathrm{SO}_{4}{ }^{2-}+\mathrm{Cl}^{\bullet}$

$\mathrm{Cl}^{\bullet}+\mathrm{Cl}^{-} \rightleftarrows \mathrm{Cl}_{2}^{\bullet-}$

Depending on the experimental conditions under consideration, several consecutive reactions may take place leading to the formation of additional chlorine-containing radicals such as $\mathrm{ClO}_{2}, \mathrm{ClO}^{*}$ and $\mathrm{HOCl}^{\bullet-}$ (Lutze et al., 2015). From these results, one can safely assume that the presence of chloride influences the distribution and relative concentration of reactive radicals, consequently altering the reactivity towards BPA degradation. Similarly to the present results, the degradation of phenol and 2,4-dichlorophenol by cobalt-activated peroxymonosulfate was promoted in the presence of chloride (Anipsitakis et al., 2006). In addition, chlorine 


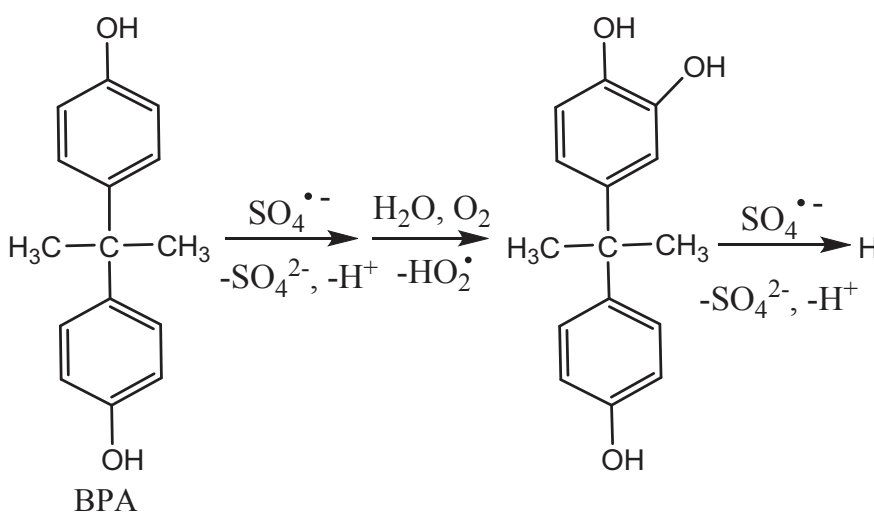<smiles>CC(C)(C)c1ccc(O)c(O)c1</smiles>

(V)

Coupling

(I) $+(\mathrm{V})$ radicals

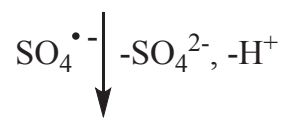<smiles>CC(C)(c1ccc(O)cc1)c1ccc(O)cc1</smiles>

(I)<smiles>Oc1ccccc1</smiles><smiles>CC(C)(C)c1ccc(O)cc1</smiles>

(VI)<smiles>CCOc1ccc(O)cc1</smiles>

(VII)<smiles>CC(C)(Oc1ccc(O)cc1)c1ccc(O)cc1</smiles>

TBP4

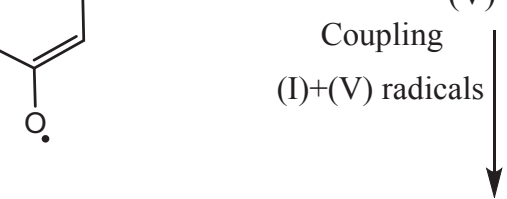

Coupling (V) radical +<smiles>CCOc1ccc(C(C)C)cc1O</smiles><smiles>CC(C)(C)c1ccc(O)cc1</smiles><smiles>CC(C)c1ccc(O)cc1</smiles><smiles>CC(C)c1ccc(OC(C)(C)c2ccc(O)c(O)c2)c(O)c1</smiles><smiles>CC(C)(O)c1ccc(O)c(O)c1</smiles>

TBP5

Fig. 9. BPA transformation pathways by radical coupling after $\beta$-scission of BPA-radical during treatment with CX/CoFe and SPS in the presence and absence of NaCl.

radicals can influence the catalytic step of $\mathrm{Fe}(\mathrm{II}) / \mathrm{Fe}(\mathrm{III})$ conversion, thus regenerating iron in its initial state of $\mathrm{Fe}(\mathrm{III})$ in the cobalt ferrite spinel:

$\mathrm{Fe}^{2+}+\mathrm{Cl}^{\bullet} \rightarrow \mathrm{Fe}^{3+}+\mathrm{Cl}^{-}$

$\mathrm{Fe}^{2+}+\mathrm{Cl}_{2}^{\bullet-} \rightarrow \mathrm{Fe}^{3+}+2 \mathrm{Cl}^{-}$

At acidic conditions ( $\mathrm{pH}<4$ ), the equilibrium between the bicarbonate ion and $\mathrm{CO}_{2}$ is completely shifted towards the latter and, in this respect, one might have expected no effect of bicarbonate on the process at the working $\mathrm{pH}$ value of 3 . Interestingly, experiments with $500 \mathrm{mg} / \mathrm{L}$ of bicarbonate (data not shown for brevity) resulted in ca $50 \%$ reduction of BPA degradation rate (i.e. from 0.093 to $0.045 \mathrm{~min}^{-1}$ ). As the solution was not purged prior to the experiment to accelerate the release of $\mathrm{CO}_{2}$ in the atmosphere, the bicarbonate ion may still be present in the solution; its detrimental effect on degradation is associated with the scavenging of both sulfate and hydroxyl radicals to form carbonate radicals (Vicente et al., 2011).

\subsection{Mechanisms and pathways of degradation}

To shed light to the mechanisms of BPA degradation in the presence and absence of chloride, samples were subject to LC-TOFMS analysis to identify transformation by-products (TBPs). The respective data are summarized in Table 2 . A total number of 11 and 15 TBPs were identified in the absence and presence of $\mathrm{NaCl}$, respectively. According to these results, polymerization pathways through radicals coupling were followed in the initial steps of degradation both in the absence and presence of $\mathrm{NaCl}$. The structures of BPA oligomers (dimers, trimers and tetramers), as well as their formation pathways are depicted in Fig. 8.

In general, for phenolic compounds, the formation of oligomers proceeds through $\mathrm{C}-\mathrm{C}$ coupling and/or $\mathrm{C}-\mathrm{O}$ coupling. Among the 
<smiles>CC(C)(C)c1ccc(O)cc1</smiles>
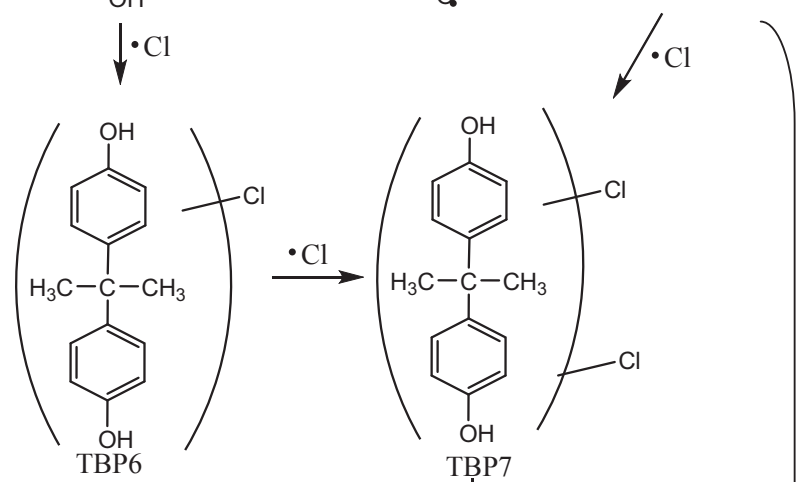

Coupling of (I), (II) radicals
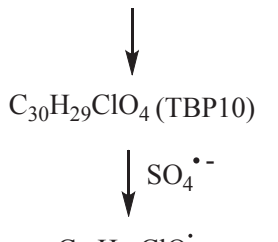

$\mathrm{SO}_{4}{ }^{--} \downarrow-\mathrm{SO}_{4}^{2-},-\mathrm{H}^{+}$

$\mathrm{SO}_{4}{ }^{-} \downarrow-\mathrm{SO}_{4}{ }^{2-},-\mathrm{H}^{+}$<smiles>CC(C)(Cl)C1(C)CCCCC1(C)c1ccc(O)cc1</smiles>

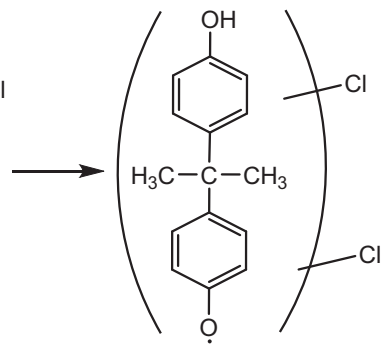

$$
\mathrm{C}_{30} \mathrm{H}_{28} \mathrm{ClO}_{4}^{\circ}
$$

Coupling $\checkmark$ with radical (I)

$\mathrm{C}_{45} \mathrm{H}_{43} \mathrm{ClO}_{6}$

(TBP14,TBP17)

Coupling of (I), (III) radicals

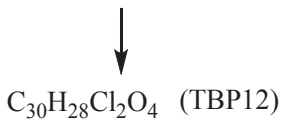

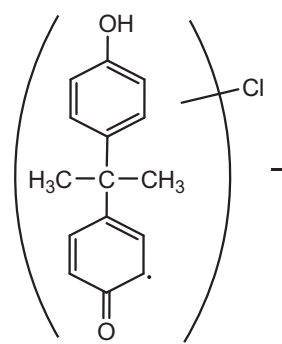

(II)
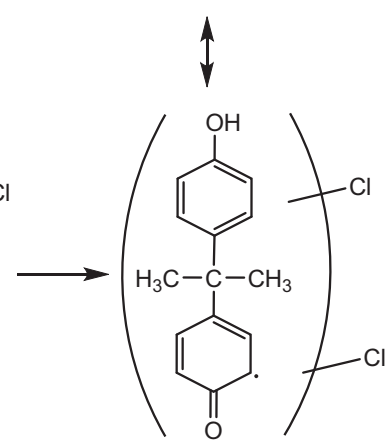

(III)

Fig. 10. BPA transformation pathways during treatment with $\mathrm{CX} / \mathrm{CoFe}$ and $\mathrm{SPS}$ in the presence of $\mathrm{NaCl}$.

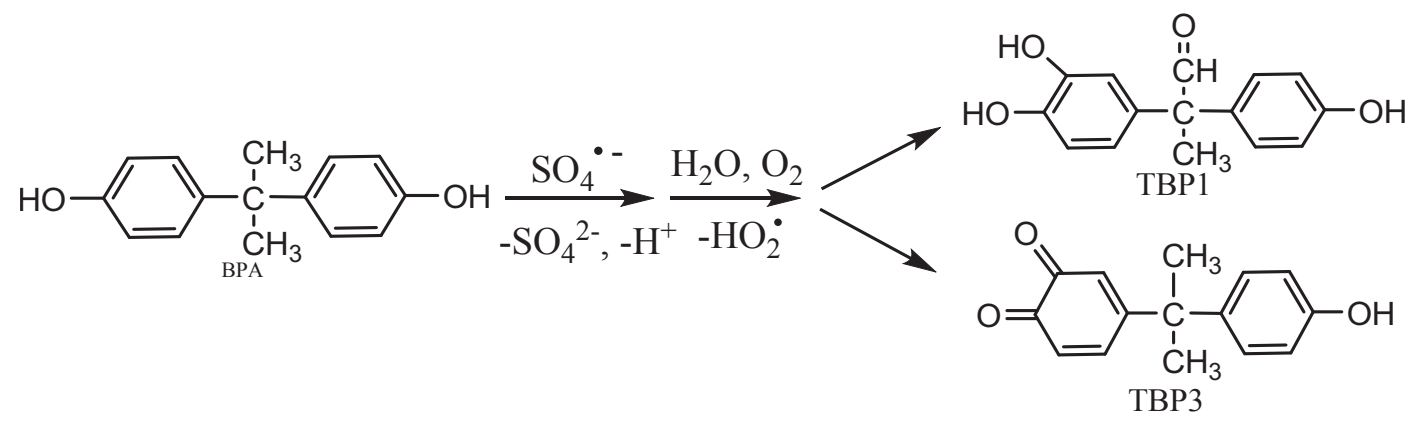

Fig. 11. Hydroxylation degradation pathways of BPA during treatment with CX/CoFe and SPS in the absence of $\mathrm{NaCl}$. 
two routes, $\mathrm{C}-\mathrm{C}$ coupling (ortho-para and ortho-ortho links) is a more favorable route, which is energetically promoted (Ežerskis and Jusys, 2001). However, it should be pointed out that TBPs with etheric structures have also been identified previously via $\mathrm{C}-\mathrm{O}$ coupling of phenoxyl radicals and their formation can also be expected (Ežerskis and Jusys, 2001).

Alongside the formation of dimers, trimers and tetramers, three other coupling TBPs (TBP2, TBP4, TBP5) have been identified both in the absence and presence of $\mathrm{NaCl}$. Their formation pathways is depicted in Fig. 9 and can be rationalized through the bimolecular coupling of BPA radicals (I) and other radicals (e.g. V, VI, VII) originated from hydrogen abstraction and $\beta$-scission of BPA and hydroxy-BPA.

Similar TBPs with oligomeric structures, as well as TBPs formed by coupling of different radicals generated during the process have also been identified during the oxidation of BPA by heat-activated persulfate (Potakis et al., 2017).

Besides the similarities in degradation pathways, some major differences are also pointed out. In the presence of $\mathrm{NaCl}$, chloroand dichloro-BPA (TBP6 and TBP7) are formed at the first stages of the reaction (Fig. 10). Chlorine-substituted BPA derivatives have also been reported in the literature during the chlorination of BPA molecule through a chlorine-substitution reaction on the aromatic ring, followed by dehydration as the proposed mechanism (Gallard et al., 2004; Hu et al., 2002). Based on literature data (Gallard et al., 2004; Hu et al., 2002), 2-chloro-BPA, 2,6'-dichloro-BPA or 2,6dichloro-BPA can be postulated.

The rapid formation of chloro- and dichloro-BPA in combination with the high abundance of their peaks justifies the fast kinetics of $\mathrm{BPA}$ degradation observed in the presence of $\mathrm{NaCl}$. The formation of TBP6 and TBP7 is followed by various chlorinated dimers and trimers, as a result of coupling reactions depicted in Fig. 10. However, in the absence of $\mathrm{NaCl}$, the degradation of BPA also proceeds through hydroxylation and oxidation reactions (Potakis et al., 2017; Sharma et al., 2016) that can occur in the aromatic ring and isopropyl group (Fig. 11). These pathways were not observed in the presence of $\mathrm{NaCl}$ within the same time framework of treatment.

Although the concentration profiles of TBPs were not possible to be followed due to their fast formation and dissipation, taking into account their relative abundance, it can be proposed that radical coupling reactions are the main transformation pathways during the first stages of the treatment, both in the presence and absence of $\mathrm{NaCl}$. Comparing the polymerization routes in the presence of $\mathrm{NaCl}$, the formation of chlorinated dimers and trimers is undoubtedly favored, proving the major role of chlorine radicals $\left(\mathrm{Cl}^{\circ}\right)$ formed through the direct reaction of $\mathrm{Cl}^{-}$with $\mathrm{SO}_{4}^{--}$radicals, as also evidenced elsewhere (Lutze et al., 2015).

\section{Conclusions}

The primary conclusions derived from this study are as follows:

1) The rate of BPA degradation is a function of the operating variables, including catalyst, oxidant and substrate concentrations, solution $\mathrm{pH}$ and treatment time. Similarly to other Fenton-like AOPs, the rate increases with increasing catalyst and oxidant concentrations, although excessive levels may introduce radical scavenging effects. Furthermore, the rate decreases with increasing substrate concentration, which highlights the need to perform studies with environmentally reasonable concentrations.

2) Unlike what typically happens in the advanced oxidation of various organics, BPA degradation in environmentally relevant matrices is faster than in pure water; this pinpoints the rather complicated interferences amongst the various organic and inorganic constituents found in actual water matrices.

3) The individual effects of humic acid, alcohols, bicarbonate and chloride ions were appraised; organics and the bicarbonate ion act as scavengers of sulfate and hydroxyl radicals, thus leading to reduced degradation, while chlorides act as a source of extra $\mathrm{Cl}$ containing radicals, thus leading to increased degradation.

4) BPA degradation is accompanied by the formation of several TBPs and occurs through (i) polymerization reactions, (ii) bimolecular coupling between BPA-radicals and other radicals, and (iii) hydroxylation/oxidation reactions. Reactions in the presence of chlorides lead to the formation of chlorinated TBPs.

\section{Acknowledgments}

Z. Frontistis would like to thank the Greek State Scholarships Foundation (IKY) for the financial support of this research through the "IKY Fellowships of Excellence for Postgraduate Studies in Greece - Siemens Programme" in the framework of the Hellenic Republic - Siemens Settlement Agreement.

Part of this work was financially supported by: Project POCI-010145-FEDER-006984 - Associate Laboratory LSRE-LCM funded by FEDER through COMPETE2020 - Programa Operacional Competitividade e Internacionalização (POCI) - and by national funds through FCT - Fundacão para a Ciencia e a Tecnologia. R.S. Ribeiro acknowledges the FCT individual Ph.D. grant SFRH/BD/94177/2013, with financing from FCT and the European Social Fund (through POPH and QREN). A.M.T. Silva acknowledges the FCT Investigator 2013 Programme (IF/01501/2013), with financing from the European Social Fund and the Human Potential Operational Programme.

\section{References}

Anipsitakis, G.P., Dionysiou, D.D., Gonzalez, M.A., 2006. Cobalt-mediated activation of peroxymonosulfate and sulfate radical attack on phenolic compounds. Implications of chloride ions. Environ. Sci. Technol. 40 (3), 1000-1007.

Bautista-Toledo, I., Ferro-Garcia, M.A., Moreno-Castilla, C., Vegas Fernandez, F.J. 2005. Bisphenol A removal from water by activated carbon. Effects of carbon characteristics and solution chemistry. Environ. Sci. Technol. 39 (16), 6246-6250.

Bennedsen, L.R., Muff, J., Sogaard, E.G., 2012. Influence of chloride and carbonates on the reactivity of activated persulfate. Chemosphere 86 (11), 1092-1097.

Darsinou, B., Frontistis, Z., Antonopoulou, M., Konstantinou, I., Mantzavinos, D., 2015. Sono-activated persulfate oxidation of bisphenol A: kinetics, pathways and the controversial role of temperature. Chem. Eng. J. 280, 623-633.

Dewil, R., Mantzavinos, D., Poulios, I., Rodrigo, M.A., 2017. New perspectives for advanced oxidation processes. J. Environ. Manag. 195, 93-99.

Ežerskis, Z., Jusys, J., 2001. Electropolymerization of chlorinated phenols on a Pt electrode in alkaline solution Part I: a cyclic voltammetry study. J. Appl. Electrochem. 31 (10), 1117-1124.

Fang, G.D., Dionysiou, D.D., Wang, Y., Al-Abed, S.R., Zhou, D.M., 2012. Sulfate radicalbased degradation of polychlorinated biphenyls: effects of chloride ion and reaction kinetics. J. Hazard. Mater. 227-228, 394-401.

Gallard, H., Leclercq, A., Croué, J.P., 2004. Chlorination of bisphenol A: kinetics and by-products formation. Chemosphere 56 (5), 465-473.

Hu, J.Y., Aizawa, T., Ookubo, S., 2002. Products of aqueous chlorination of BPA and the estrogenic activity. Environ. Sci. Technol. 36 (9), 1980-1987.

Huang, Y.Q., Wong, C.K.C., Zheng, J.S., Bouwman, H., Barra, R., Wahlstrom, B., Neretin, L., Wong, M.H., 2012. Bisphenol A (BPA) in China: a review of sources, environmental levels, and potential human health impacts. Environ. Int. 42 91-99.

Lin, Y.T., Liang, C., Chen, J.H., 2011. Feasibility study of ultraviolet activated persulfate oxidation of phenol. Chemosphere 82 (8), 1168-1172.

Liu, H., Bruton, T.A., Doyle, F.M., Sedlak, D.L., 2014. In situ chemical oxidation of contaminated groundwater by persulfate: decomposition by $\mathrm{Fe}(\mathrm{III})$ - and Mn(IV)-containing oxides and aquifer materials. Environ. Sci. Technol. 48 (17), 10330-10336.

Lutze, H.V., Kerlin, N., Schmidt, T.C., 2015. Sulfate radical-based water treatment in presence of chloride: formation of chlorate, inter-conversion of sulfate radicals into hydroxyl radicals and influence of bicarbonate. Water Res. 72, 349-360.

Matzek, L.W., Carter, K.E., 2016. Activated persulfate for organic chemical degradation: a review. Chemosphere 151, 178-188.

Nidheesh, P.V., 2015. Heterogeneous Fenton catalysts for the abatement of organic pollutants from aqueous solution: a review. RSC Adv. 5, 40552-40577.

Oehlmann, J., Oetken, M., Schulte-Oehlmann, U., 2008. A critical evaluation of the 
environmental risk assessment for plasticizers in the freshwater environment in Europe, with special emphasis on bisphenol A and endocrine disruption. Environ. Res. 108 (2), 140-149.

Potakis, N., Frontistis, Z., Antonopoulou, M., Konstantinou, I., Mantzavinos, D., 2017. Oxidation of bisphenol A in water by heat-activated persulfate. J. Environ. Manag. 195, 125-132.

Qi, C., Liu, X., Zhao, W., Lin, C., Ma, J., Shi, W., Sun, Q., Xiao, H., 2015. Degradation and dechlorination of pentachlorophenol by microwave-activated persulfate. Environ. Sci. Pollut. Res. 22 (6), 4670-4679.

Ribeiro, R.S., Silva, A.M.T., Figueiredo, J.L., Faria, J.L., Gomes, H.T., 2016a. Catalytic wet peroxide oxidation: a route towards the application of hybrid magnetic carbon nanocomposites for the degradation of organic pollutants. A review. Appl. Catal. B Environ. 187, 428-460.

Ribeiro, R.S., Frontistis, Z., Mantzavinos, D., Venieri, D., Antonopoulou, M. Konstantinou, I., Silva, A.M.T., Faria, J.L., Gomes, H.T., 2016b. Magnetic carbon xerogels for the catalytic wet peroxide oxidation of sulfamethoxazole in environmentally relevant water matrices. Appl. Catal. B Environ. 199, 170-186. Sharma, J., Mishra, I.M., Kumar, V., 2016. Mechanistic study of photo-oxidation of bisphenol A (BPA) with hydrogen peroxide $\left(\mathrm{H}_{2} \mathrm{O}_{2}\right)$ and sodium persulfate (SPS). J. Environ. Manag. 166, 12-22.

Tsitonaki, A., Petri, B., Crimi, M., Mosbaek, H., Siegrist, R.L., Bjerg, P.L., 2010. In situ chemical oxidation of contaminated soil and groundwater using persulfate: a review. Crit. Rev. Environ. Sci. Technol. 40 (1), 55-91.

Vandenberg, L.N., Hauser, R., Marcus, M., Olea, N., Welshons, W.V., 2007. Human exposure to bisphenol A (BPA). Reprod. Toxicol. 24 (2), 139-177.

Vicente, F., Santos, A., Romero, A., Rodriguez, S., 2011. Kinetic study of diuron oxidation and mineralization by persulphate: effects of temperature, oxidant concentration and iron dosage method. Chem. Eng. J. 170 (1), 127-135.

Zhao, L., Hou, H., Fujii, A., Hosomi, M., Li, F., 2014. Degradation of 1,4-dioxane in water with heat- and $\mathrm{Fe}^{2+}$-activated persulfate oxidation. Environ. Sci. Pollut. Res. 21 (12), 7457-7465. 